\title{
Electrophysiological Basis of Fecal Incontinence and Its Implications for Treatment
}

\author{
Elroy Patrick Weledji \\ Department of Surgery and Obstetrics and Gynecology, Faculty of Health Sciences, University of Buea, Buea, Cameroon
}

The majority of patients with neuropathic incontinence and other pelvic floor conditions associated with straining at stool have damage to the pudendal nerves distal to the ischial spine. Sacral nerve stimulation appears to be a promising innovation and has been widely adopted and currently considered the standard of care for adults with moderate to severe fecal incontinence and following failed sphincter repair. From a decision-to-treat perspective, the short-term efficacy is good (70\%-80\%), but the long-term efficacy of sacral nerve stimulation is around $50 \%$. Newer electrophysiological tests and improved anal endosonography would more effectively guide clinical decision making.

Keywords: Incontinence; Electrophysiology; Biofeedback; Sacral nerve stimulation; Neosphincter

\section{INTRODUCTION}

Fecal incontinence is a debilitating condition that affects approximately $2 \%-20 \%$ of the adult population $[1,2]$. It is more common in females, and with advancing age, it is the second most common cause of admission to a nursing home [3]. The most common cause in women is obstetric trauma (Table 1) [1, 4]. Even a normal vaginal delivery is associated with a degree of damage to the nerve supply of the pelvic floor. Although prevention of obstetric trauma altogether is unlikely, obstetricians are becoming aware of the need to recognize injuries at the time of delivery and of the requirement that these injuries be repaired by appropriately skilled personnel [5]. Increased awareness among patients and clinicians that fecal incontinence can be successfully treated in the majority of patients will lead to an increase in referrals [6, 7]. A neurophysiological assessment of the anorectum includes an assessment of the conduction of the pudendal and spinal nerves, as well as electromyography $(\mathrm{EMG})$ of the sphincter. Anal endosonography

Received: December 19, 2016 • Accepted: March 30, 2017

Correspondence to: Elroy Patrick Weledji, M.D.

Department of Surgery and Obstetrics and Gynecology, Faculty of Health

Sciences, University of Buea, PO Box 126, Limbe, S.W. Region, Cameroon

Tel: +237-699922144, Fax: +237-33322272

E-mail: elroypat@yahoo.co.uk

(c) 2017 The Korean Society of Coloproctology

This is an open-access article distributed under the terms of the Creative Commons Attribution NonCommercial License (http://creativecommons.org/licenses/by-nc/4.0) which permits unrestricted noncommercial use, distribution, and reproduction in any medium, provided the original work is properly cited.
(AES) is now superior to EMG in mapping sphincter defects and is so much better tolerated by patients that EMG has largely become a research tool [8]. Although no clear correlation has been found between manometric neurophysiological testing and clinical symptomatology in patients with idiopathic fecal incontinence, performing these tests before surgery may predict long-term outcome $[7,9]$. Anorectal investigation has revealed a large group of parous women with occult sphincter trauma that may have a clinical impact as these women get older [5,9]. Newer electrophysiological tests and improved AES would more effectively select patients for appropriate treatment and, thus, lead to better outcome.

\section{ELECTROPHYSIOLOGY}

The impetus to develop electrophysiological techniques for the purpose of investigating sphincter function in order to determine the cause of fecal incontinence came from the work of Parks and Swash [10]. They identified histological changes in the anal sphincter, showing evidence of denervation of the muscle. Standard electromyographic and nerve conduction studies used elsewhere in the body were adapted to study the anal sphincter and other pelvic floor muscles. These tests have provided a detailed understanding of the pathophysiology of incontinence and several other conditions affecting the pelvic floor muscles. In patients with fecal incontinence, once the anal sphincter has been shown manometrically to be weak, anorectal physiological studies are used increasingly by coloproctologists to determine the cause for the muscle weakness $[6,9,10]$. 
Table 1. Etiology of fecal continence [59]

\begin{tabular}{lllll}
\hline Trauma & \multicolumn{1}{c}{ Colorectal disease } & \multicolumn{1}{c}{ Congenital } & Neurological & Miscellaneous \\
\hline Obstetric & Hemorrhoids & Spinal bifida & Cerebral & Behavioural \\
Surgical & Rectal prolapse & Operations for imperforate anus & Spinal & Impaction \\
Accident/war injury & Inflammatory bowel disease & Hirschsprung disease & Peripheral & Encopresis \\
& Tumors & & & \\
\hline
\end{tabular}

\section{Pudendal nerve terminal motor latency}

In 1984, Kiff and Swash [11] demonstrated that trans-stimulation of the pudendal nerves induced ejaculation in patients with paraplegia. This is because they carry the parasympathetic component for genital erection (pelvic splanchnic nerve - S 2, 3, 4 roots), as well [12]. This initiated the assessment tests of motor conduction in the distal part of the pudendal nerve, which is most vulnerable to injury [13]. Weakness of the external anal sphincter due to pudendal nerve damage may occur in 2 ways - a direct stretch-induced injury during vaginal delivery and chronic straining at stool. In addition, damage to the pelvic nerves causing perineal descent, in turn, leads to pudendal nerve stretch [14]. Thus, abnormal pudendal nerve motor latency (PNML) occurs in patients with neurogenic fecal incontinence [1]. Stretch-induced injury arises because of the anatomy of the pudendal nerves. The position of the nerves is fixed as they pass behind the ischial spine, but distal to this point, the nerves are able to move freely and may be damaged if excessive floor descent occurs. In normal subjects, the pelvic floor descends up to $2 \mathrm{~cm}$ during straining down, but a descent of up to $3 \mathrm{~cm}$ is abnormal. Perineal descent of this magnitude will produce a stretch of the pudendal nerve of $20 \%$ above its usual length, and because a stretch of only $12 \%$ produces nerve damage, that abnormal perineal descent is postulated to cause pudendal nerve damage $[15,16]$.

Studies have shown a linear correlation and a significant relationship between perineal descent and pudendal latency $[11,13]$. Abnormal perineal descent and nerve damage are caused by chronic straining at stool and difficult vaginal delivery [1, 4-6, 13]. Repeated neuropraxia in the former over a long period of time leads to permanent nerve damage $[16,17]$. Abnormal pudendal latency is also found in patients with combined fecal and urinary incontinence $[13,18]$, incontinence persisting after rectopexy for prolapse [19], chronic constipation [20], hemorrhoids [21], symptomatic uterovaginal prolapse [22], and solitary rectal ulcer syndrome [23]. Pudendal latencies should be measured bilaterally because nerve damage is sometimes asymmetric [11]. Normal pudendal latencies are found in patients with diabetes and normal continence, although prolonged pudendal latencies have been found in patients with diabetics with or without incontinence [24]. Pudendal latency increases with age in normal subjects, and it is higher in men than women, but no sex differences have been found in patients with constipation [16].

Pudendal neuropathy is not a predictor of surgical intervention
Table 2. Cleveland Clinic Scoring system for assessment of fecal incontinence [59]

\begin{tabular}{lccccc}
\hline & Never & Rarely & Sometimes & Usually & Always \\
\hline Solids & 0 & 1 & 2 & 3 & 4 \\
Liquids & 0 & 1 & 2 & 3 & 4 \\
Flatus & 0 & 1 & 2 & 3 & 4 \\
Use of pad & 0 & 1 & 2 & 3 & 4 \\
Lifestyle alteration & 0 & 1 & 2 & 3 & 4 \\
\hline
\end{tabular}

Rarely, less than once a month; Sometimes, more than once a month, but lees than once a week; Usually, more than once a week, but less than once a day; Always, more than once a day.

for fecal incontinence, but independent predictors include the presence of a prolapse, a functional sphincter length $<1 \mathrm{~cm}$, an external anal sphincter defect, and a Cleveland Clinic Incontinence Score $\geq 10$ (Table 2) [25]. In clinical assessments, pudendal nerve studies are of particular value in patients with fecal incontinence, but not in those with solitary rectal ulcer syndrome, hemorrhoids or the complexity of obstructive defecation syndrome as many of the associated problems or pathologies may not be immediately apparent. In addition, the PNML is operator dependent and has a poor correlation with clinical symptoms and histological findings. The investigation only examines the fastest conducting fibers of the pudendal nerve, so the PNML can still be normal even in the presence of abnormal sphincter innervation [11]. Pudendal nerve testing may not, therefore, contribute to surgical decision making in patients with fecal incontinence [25]. The American Gastroenterology Association does not, therefore, recommend the use of pudendal nerve testing for the evaluation of patients with fecal incontinence [26].

The perineal branch of the pudendal nerve innervates the striated urethral sphincter muscle, and the course of the perineal nerve to the urethral sphincter is longer than that of the inferior rectal nerve to the external anal sphincter. Thus, the perineal nerve latency is longer than the pudendal latency. The perineal nerve latency is measured in the same way as the pudendal latency by using an intrarectal nerve-stimulating device, but the muscle response is recorded in the urethral sphincter by using a bipolar ring electrode mounted on a urethral Foley catheter [18]. Perineal nerve latency is a useful measure of denervation in patients with urinary stress incontinence, although clinicians rely mainly on the results of urodynamic studies. The perineal motor 
latency is greater in patients with double incontinence than it is in those with fecal or urinary incontinence alone [18]. However, because perineal latency is more difficult and time consuming to measure than pudendal latency, and has the added risk of introducing urinary sepsis, perineal latency has remained a research tool in most laboratories.

\section{Spinal motor latency}

Transcutaneous stimulation of the sacral motor nerve roots provides further information on the innervation of the pelvic floor. In patients with neuropathic fecal and urinary incontinence, damage to the external anal sphincter and to the puborectalis and the levator ani muscles has been shown to occur [27, 28]. Because the nerve supply to the puborectalis and levators is almost entirely from direct pelvic nerves $(\mathrm{S} 3,4)$, it follows that these nerves have been injured. The mechanism has not been clearly identified but it has been assumed that there are not subject to the same stretch injury as the pudendal nerves distal to the ischial spines. In parous women, direct pressure of the fetal head on the nerves during the second stage of labor may cause nerve damage [29]. Other proximal nerve lesions are considered as supranuclear or infranuclear, depending on their relation to the Onuf nucleus (Table 1) [30]. Infranuclear (lower motor neurone) lesions result from damage to the sacral nerve roots in the pelvis or within the cauda equina. Conditions in the pelvis may include primary tumors or cysts whereas cauda equina disease may result from sacral spondylosis, disc prolapse, trauma, or intraspinal neoplasms.

Transcutaneous stimulation of the cauda equina over the lumbar spine measures conduction along the cauda equina, the sacral plexus, and the branches from the plexus. Thus, injury manifested as a slowing of conduction may be regarded as occurring in (1) the cauda equina; (2) the pelvis, affecting the sacral plexus and the direct branches innervating the levator ani (S4); or (3) the pudendal nerves distal to the ischial spines $(\mathrm{S} 2,3,4)$. The evoked response can be recorded using standard EMG needles inserted at three sites: the puborectalis, external sphincter and the urethral sphincter [31]. If a stretch-induced injury to the pudendal nerves exists, then the conduction time from the spinal cord (L1 stimulation) to the external sphincter (spinal latency) will be prolonged as will the pudendal nerve terminal motor latency. If the injury is above the level of the ischial spine, then the spinal latency (L1 stimulation) will be prolonged, and the pudendal latency from L4 stimulation will be normal.

Table 3. Transcutaneous spinal stimulation latencies in normal subjects [23]

\begin{tabular}{lccc}
\hline Recording site & L1 latency (msec) & L4 latency (msec) & \multicolumn{1}{c}{ SLR } \\
\hline External anal sphincter & $5.5 \pm 0.4$ & $4.4 \pm 0.4$ & $1.33 \pm 0.1$ \\
Puborectalis & $4.8 \pm 0.4$ & $3.7 \pm 0.4$ & $1.3 \pm 0.1$ \\
\hline
\end{tabular}

Values are presented as mean \pm standard deviation.

SLR, spinal latency ratio.
A spinal latency ratio (SLR) is calculated to determine whether the abnormality lies within the cauda equina or beyond that site. If the abnormality lies distal to the caudal equina, then the latency from both sides will be prolonged, and the SLR is constant. If the abnormality is within the cauda equina, then only the L1 latency will be prolonged as the SLR will be increased [30]. Thus, by comparing the latency times between the 2 levels, the latency of the motor component of the cauda equina can be assessed. Up to $23 \%$ of patients with idiopathic fecal incontinence will have cauda equina delay $[32,33]$. Normal values of the spinal latency and the SLR are given in Table 3 [18].

\section{THE CONTINENCE FACTORS}

The continence factors are the involuntary, smooth, internal anal sphincter (passive continence) controlled by the parasympathetic and sympathetic nervous system; the voluntary, striated, external anal sphincter (active : urge continence) controlled by the pudendal nerve $(S 2,3,4)$; the ano-rectal angle produced by the striated puborectalis sling of the pelvic floor (lower edge of the levator ani [S4]); the anal cushions and mucosal folds; and the lateral abdominal pressure on the upper anterior part of the lower rectum. The rectum is supplied by both sympathetic and parasympathetic nerves. The sympathetic nerves from the superior hypogastric plexus contract the smooth muscle sphincters, relax the bowel, and transmit pain whereas the parasympathetic nerves in the pelvis splanchnic nerve $(\mathrm{S} 2,3,4)$ of the inferior hypogastric plexus relax smooth muscle sphincters, contract the bowel, and transmit the feeling of fullness (Fig. 1) [12]. The lower third of the rectum is normally empty except during defecation when it distends into the ischioanal fossa, as necessary. The upper two-thirds is disten-

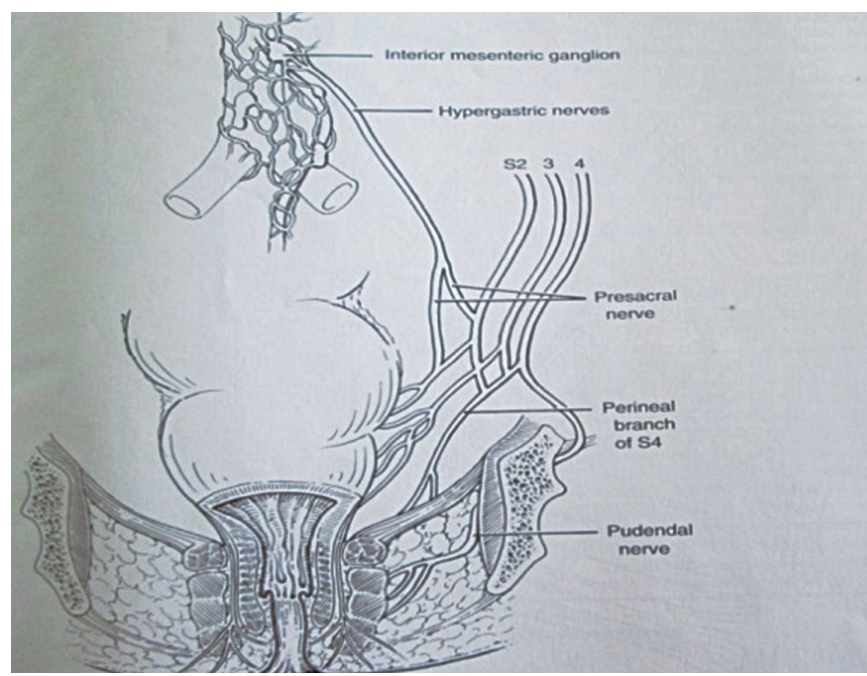

Fig. 1. Schematic diagram of the innervation of the rectum and anal canal. Reprinted from Weledji et al. Int J Surg Res 2014;3:7-14, with permission of Scientific \& Academic Publishing [12]. 
sible into the abdominal cavity and stores feces only in constipation. Normally, feces are stored in the colon above and only enters the rectum just before defecation during the mass movement of feces from above.

\section{TREATMENT OF FECAL INCONTINENCE}

The treatment of fecal incontinence depends on its etiology [34]. The majority of patients who have a specific sphincter defect following obstetric trauma, which has been identified by using endoanal ultrasound, will benefit from anterior sphincter repair in the short term. If the primary problem is a specific sphincter defect, an anterior sphincter repair with levatorplasty is preferred [35-40]. However, many of these patients will have a degree of coexisting neuropathic damage to the pelvic floor, particularly if they have undergone multiple vaginal deliveries [38]. Although the presence of neuropathic damage in these patients does not alter the initial surgical management [25], it does influence the prognosis as seen in the poor long-term benefit (40\%) from post anal repair or a total pelvic floor repair except for those with anatomical defects such as a rectocele or an abnormal perineal descent $[39,40]$. The etiology of the progression of the pudendal nerve damage over time is not known. However, since the advent of sacral nerve stimulation (SNS), total pelvic floor repair has become obsolete. Those in whom the incontinence is neurological in origin may benefit from a conservative approach initially [7].

\section{Conservative treatment}

Following careful assessment and investigation, the majority of patients may benefit from conservative treatment. Patients with severe neuropathic incontinence are best treated by using intensive conservative management with control of stool consistency and with physiotherapy or pelvic floor retraining (biofeedback) before surgical treatment is considered [41]. Surgical options are limited as many of these patients do not have any sphincter defect amenable to repair, and sphincter procedures, postanal repair, and total pelvic floor repair have proven ineffective $[5,42]$.

\section{Biofeedback}

Biofeedback is particularly useful in patients who primarily have a sensory problem in the anal canal leading to insensible loss of feces. Patients are trained using either electromyographic or manometric feedback to improve the strength of their anal sphincters and if this is coupled with an intrarectal balloon, their rectal sensory awareness may be improved [43]. More specific physiotherapy using either interferential treatment of the pelvic floor and, in particular, trophic stimulation via an anal plug electrode, which uses electrical impulses designed to mimic the train of signals along the pudendal nerve, can be extremely successful. The precise role of electrical stimulation of the pelvic floor is unclear, but the results are almost equivalent to those obtained by using postanal repair $[44,45]$. Biofeedback training can lead to improvements in $70 \%$ of the patients [42] and in patients with structural defects of the anal sphincters [46-48].

\section{Sacral nerve stimulation}

SNS is a promising innovation that will probably become the treatment of choice for neuropathic fecal incontinence and following failed sphincter repair. As SNS has been used in the treatment of urinary incontinence, a similar technique has been utilized for fecal incontinence with promising results $[49,50]$. For patients in whom the primary etiology appears to be neurogenic and in whom preoperative investigations have failed to reveal a sphincter defect, a trial of SNS is justified $[50,51]$. SNS works by electrical stimulation of the sacral (S2-S4) nerve roots, thereby producing a combination of anal sphincter augmentation and modulation of spinal/supraspinal pathways. It benefits from a 2-stage procedure, which enables the patient to assess acceptability, and the clinician to evaluate efficacy prior to permanent implantation. It entails an initial trial stimulation. A percutaneous wire is inserted under general or local anesthesia into the second, third, or fourth sacral foramen. Successful positioning is indicated by contraction of the pelvic floor and flexion of the ipsilateral great toe. The wire is connected to an external stimulator, and the patient is asked to keep a bowel diary for the 2 to 3 weeks of temporary stimulation, which allows the clinician to quantify the degree of response. A positive response is defined as a reduction in incontinence episodes or an incontinence score of $\geq 50 \%$ during the stimulation period [52]. If successful, a permanent indwelling stimulator can be inserted. A permanent tined electrode is implanted via a percutaneous approach. The implanted pulse generator is connected and inserted into a subcutaneous pocket created in the ipsilateral buttock, and the settings can be altered transcutaneously by the clinician or patient [51].

The trial stimulation is associated with a very low level of complications and with a complication rate of $5 \%-10 \%$ for insertion of a permanent implant [53]. Initial reports have suggested improvements in continence in approximately $70 \%-80 \%$ of patients who had been permanently implanted [54]. The technique appears to benefit patients who have an intact anal sphincter on ultrasound and some preservation of pudendal nerve function. Early studies have demonstrated the benefit of sacral neuromodulation in patients with spinal cord injuries [55], and an intact anal sphincter would also appear not to be necessary for success with SNS in patients with fecal incontinence [56]. More recent studies have demonstrated that in the medium term, SNS is an effective option for patients with neuropathic incontinence who have failed conservative treatment and for whom the only viable alternative option would be a stoma $[57,58]$. For young patients who have severe sphincter injuries, a failed sphincter repair, or insufficient residual sphincter, consideration should be given to either SNS or some form of sphincter augmentation or artificial bowel sphincter $[59,60]$.

Treatment strategies for adult FI are summarized in the National Institute for Health and Care Excellence 2007 guidance, which 
supports the use of SNS for the treatment of adult FI refractory to conservative measures [7]. SNS has been widely adopted and is currently considered the standard of care for adults with moderate to severe fecal incontinence [60-69]. Although the short-term efficacy of SNS is good, with $70 \%-80 \%$ of patients experiencing symptom improvement, $25 \%$ of patients suffer loss of efficacy with time, and a further $2 \%-5 \%$ suffer irresolvable complications and undergo explantation $[65,66]$. Although published longerterm studies with larger numbers of patients and reasonable follow-up have confirmed the effectiveness of SNS, from a decisionto-treat perspective, the long-term efficacy is around 50\% [67-71]. However, SNS is very costly [3].

\section{Posterior tibial nerve stimulation}

Posterior tibial nerve stimulation (PTNS) is a noninvasive neuromodulation method used for the treatment of patients with fecal incontinence. The PTN contains sensory, motor, and autonomic fibers that emerge from L4 and L5, as well as S1 to S3 $[34,60]$. PTNS is not as effective as SNS, but is less expensive and complicated [61, 62]. Afferent impulses (200 msec, $10 \mathrm{~mA}, 10 \mathrm{~Hz}$ current) to both tibialis posterior nerves emanate from electrodes placed above the medial malleolus. The treatment utilizes 20 PTNS sessions per month. It is usually used after failed conservative and behavioral interventions $[63,64]$. Because frequent treatment sessions are required, it may be more suitable as an in-house procedure for elderly patients in a nursing home.

\section{Sphincter augmentation}

Sphincter augmentation procedures can be used for patients who are not suitable for direct repair or in whom a previous repair has failed. Various muscles, including the gluteus maximus, sartorius, adductor lunges and, most commonly, gracilis, have been used in sphincter augmentation. The advantage of the gracilis muscle is that it is the most superficial muscle in the medial aspect of the thigh and is approximately the right size. In addition, its blood and nerve supply enter proximally. Thus, a distal division of the muscle does not compromise the blood supply. The operation has been superseded by the electrically stimulated gracilis neosphincter, which is a better physiological replacement (with the resting tone of the prepondering slow switch fibres) of the external sphincter [72-75]. The techniques have evolved and now use intramuscular electrodes rather than direct stimulation of the nerve to the gracilis, which is associated with significantly greater mechanical problems, such as perineural fibrosis and electrode migration, that require revisional surgery $[76,77]$.

\section{Neosphincter}

The artificial bowel sphincter for the treatment of patients with fecal incontinence has not proved to be as successful as the artificial sphincter for the treatment of patients with urinary incontinence has. It was associated with significant complications in a multicenter cohort study: $45 \%$ of patients required revisional sur- gery, and $37 \%$ required removal of the device. In those patients who retained their device, continence was satisfactory, being over $80 \%$ [78]. In centers at which specialists have particular experience in the technique, the artificial bowel sphincter appears to be a valuable alternative for patients, but a very high incidence of infective complications has been reported [79]. In the elderly, who have poor prognostic factors, not attempting reconstructive surgery, but offering a permanent colostomy, which may well restore quality of life in the least traumatic way, may be in the patient's best interest [67].

\section{Magnetic sphincter}

The FENIX magnetic sphincter augmentation (MSA) device is a novel continence device consisting of a flexible band of interlinked titanium beads with magnetic cores that is placed around the anal canal to augment anal sphincter tone through passive attraction of the beads. Preliminary studies suggest that the FENIX MSA is safe, but efficacy data are limited. A rigorous evaluation is required prior to widespread adoption. The SaFaRI trial is a randomized, controlled, unblinded trial that will investigate the use of the FENIX MSA, as compared to SNS, for the treatment of adults with fecal incontinence resistant to conservative management [80]. The primary endpoint is success, as defined by device in use and $\geq 50 \%$ improvement in the Cleveland Clinic Incontinence Score at 18 months postrandomization. Secondary endpoints include complications, quality of life, and cost effectiveness. SaFaRI will rigorously evaluate the new technology (FENIX MSA) for the treatment of adults with fecal incontinence and for its safe and controlled introduction into current clinical practice.

\section{CONCLUSION}

Although the mechanism of action of SNS remains unknown, it appears to benefit the majority of patients with fecal incontinence, particularly those with neuropathic damage to the pelvic floor. As prevention of obstetric trauma altogether is unlikely, the use of SNS will increase in the future. The indications for stimulated neosphincter formation or a magnetic sphincter are expanding, but the use of the artificial bowel sphincter is speculative. Newer electrophysiological tests and improved AES would guide clinical decision making and render a better outcome.

\section{CONFLICT OF INTEREST}

No potential conflict of interest relevant to this article was reported.

\section{ACKNOWLEDGMENTS}

I acknowledge the European Society of Coloproctology (ESCP) for granting me a Medtronic-sponsored travel clinical fellowship in pelvic floor surgery at St. Gallen, Switzerland. I also acknowl- 
edge my supervisor Dr. Lukas Marti of the Pelvic Floor Unit.

\section{REFERENCES}

1. Wald A. Clinical practice. Fecal incontinence in adults. $\mathrm{N}$ Engl J Med 2007;356:1648-55.

2. Ng KS, Sivakumaran Y, Nassar N, Gladman MA. Fecal incontinence: community prevalence and associated factors--a systematic review. Dis Colon Rectum 2015;58:1194-209.

3. Dudding TC, Meng Lee E, Faiz O, Parés D, Vaizey CJ, McGuire A, et al. Economic evaluation of sacral nerve stimulation for faecal incontinence. Br J Surg 2008;95:1155-63.

4. Guise JM, Morris C, Osterweil P, Li H, Rosenberg D, Greenlick M. Incidence of fecal incontinence after childbirth. Obstet Gynecol 2007;109(2 Pt 1):281-8.

5. Fitzpatrick M, O'Herlihy C. Short-term and long-term effects of obstetric anal sphincter injury and their management. Curr Opin Obstet Gynecol 2005;17:605-10.

6. Pirro N, Sastre B, Sielezneff I. What are the risk factors of anal incontinence after vaginal delivery? J Chir (Paris) 2007;144:197202.

7. National Collaborating Centre for Acute Care (UK). Faecal incontinence: the management of faecal incontinence in adults. London: National Collaborating Centre for Acute Care (UK); 2007.

8. Law PJ, Kamm MA, Bartram CI. A comparison between electromyography and anal endosonography in mapping external anal sphincter defects. Dis Colon Rectum 1990;33:370-3.

9. Zutshi M, Salcedo L, Hammel J, Hull T. Anal physiology testing in fecal incontinence: is it of any value? Int J Colorectal Dis 2010; 25:277-82.

10. Parks A, Swash M. Denervation of the anal sphincter causing idiopathic anorectal incontinence. J R Coll Surg Edinb 1979;24:94-6.

11. Kiff ES, Swash M. Slowed conduction in the pudendal nerves in idiopathic (neurogenic) faecal incontinence. Br J Surg 1984;71: 614-6.

12. Weledji EP, Eyongetta D. Anatomical basis of autonomic dysfunction in coloproctology. Int J Surg Res 2014;3:7-14.

13. Swash M, Snooks SJ, Henry MM. Unifying concept of pelvic floor disorders and incontinence. J R Soc Med 1985;78:906-11.

14. Beersiek F, Parks AG, Swash M. Pathogenesis of ano-rectal incontinence. A histometric study of the anal sphincter musculature. J Neurol Sci 1979;42:111-27.

15. Sunderland S. Nerves and nerve injuries. 2nd ed. Edinburgh: Churchill Livingstone; 1978.

16. Jameson JS, Chia YW, Kamm MA, Speakman CT, Chye YH, Henry MM. Effect of age, sex and parity on anorectal function. Br J Surg 1994;81:1689-92.

17. Jorge JM, Wexner SD, Ehrenpreis ED, Nogueras JJ, Jagelman DG. Does perineal descent correlate with pudendal neuropathy? Dis Colon Rectum 1993;36:475-83.

18. Snooks SJ, Barnes PR, Swash M. Damage to the innervation of the voluntary anal and periurethral sphincter musculature in inconti- nence: an electrophysiological study. J Neurol Neurosurg Psychiatry 1984;47:1269-73.

19. Setti Carraro P, Nicholls RJ. Postanal repair for faecal incontinence persisting after rectopexy. Br J Surg 1994;81:305-7.

20. Vaccaro CA, Wexner SD, Teoh TA, Choi SK, Cheong DM, Salanga VD. Pudendal neuropathy is not related to physiologic pelvic outlet obstruction. Dis Colon Rectum 1995;38:630-4.

21. Bruck CE, Lubowski DZ, King DW. Do patients with haemorrhoids have pelvic floor denervation? Int J Colorectal Dis 1988;3: 210-4.

22. Spence-Jones C, Kamm MA, Henry MM, Hudson CN. Bowel dysfunction: a pathogenic factor in uterovaginal prolapse and urinary stress incontinence. Br J Obstet Gynaecol 1994;101:14752.

23. Snooks SJ, Nicholls RJ, Henry MM, Swash M. Electrophysiological and manometric assessment of the pelvic floor in the solitary rectal ulcer syndrome. Br J Surg 1985;72:131-3.

24. Pinna Pintor M, Zara GP, Falletto E, Monge L, Demattei M, Carta $\mathrm{Q}$, et al. Pudendal neuropathy in diabetic patients with faecal incontinence. Int J Colorectal Dis 1994;9:105-9.

25. Cooper EA, De-Loyde KJ, Young CJ, Shepherd HL, Wright C. Pudendal nerve testing does not contribute to surgical decision making following anorectal testing in patients with faecal incontinence. Int J Colorectal Dis 2016;31:1437-42.

26. Barnett JL, Hasler WL, Camilleri M. American Gastroenterological Association medical position statement on anorectal testing techniques. American Gastroenterological Association. Gastroenterology 1999;116:732-60.

27. Smith AR, Hosker GL, Warrell DW. The role of partial denervation of the pelvic floor in the aetiology of genitourinary prolapse and stress incontinence of urine. A neurophysiological study. Br J Obstet Gynaecol 1989;96:24-8.

28. Snooks SJ, Henry MM, Swash M. Anorectal incontinence and rectal prolapse: differential assessment of the innervation to puborectalis and external anal sphincter muscles. Gut 1985;26:4706.

29. Snooks SJ, Swash M, Henry MM, Setchell M. Risk factors in childbirth causing damage to the pelvic floor innervation. Int J Colorectal Dis 1986;1:20-4.

30. Lubowski DZ, Swash M, Henry MM. Neural mechanisms in disorders of defaecation. In: Grundy D. Read NW, editors. Gastrointestinal neurophysiology. London: Bailliere Tindall; 1988. p. 20123.

31. Merton PA, Hill DK, Morton HB, Marsden CD. Scope of a technique for electrical stimulation of human brain, spinal cord, and muscle. Lancet 1982;2:597-600.

32. Snooks SJ, Swash M, Henry MM. Abnormalities in central and peripheral nerve conduction in patients with anorectal incontinence. J R Soc Med 1985;78:294-300.

33. Setti Carraro P, Kamm MA, Nicholls RJ. Long-term results of postanal repair for neurogenic faecal incontinence. Br J Surg 1994;81:140-4. 
34. Whitehead WE, Rao SS, Lowry A, Nagle D, Varma M, Bitar KN, et al. Treatment of fecal incontinence: state of the science summary for the National Institute of Diabetes and Digestive and Kidney Diseases workshop. Am J Gastroenterol 2015;110:138-46.

35. Oliveira L, Pfeifer J, Wexner SD. Physiological and clinical outcome of anterior sphincteroplasty. Br J Surg 1996;83:502-5.

36. Weledji EP, Elong A, Verla V. Secondary repair of severe chronic fourth-degree perineal tear due to obstetric trauma. J Surg Case Rep 2014;2014(5). pii: rju034. https://doi.org/10.1093/jscr/rju034.

37. Ahmad M, McCallum IJ, Mercer-Jones M. Management of faecal incontinence in adults. BMJ 2010;340:c2964.

38. Gilliland R, Altomare DF, Moreira H Jr, Oliveira L, Gilliland JE, Wexner SD. Pudendal neuropathy is predictive of failure following anterior overlapping sphincteroplasty. Dis Colon Rectum 1998;41:1516-22.

39. Pinho M, Ortiz J, Oya M, Panagamuwa B, Asperer J, Keighley MR. Total pelvic floor repair for the treatment of neuropathic fecal incontinence. Am J Surg 1992;163:340-3.

40. Laurberg S, Swash M, Henry MM. Effect of postanal repair on progress of neurogenic damage to the pelvic floor. Br J Surg 1990; 77:519-22.

41. Heymen S, Jones KR, Ringel Y, Scarlett Y, Whitehead WE. Biofeedback treatment of fecal incontinence: a critical review. Dis Colon Rectum 2001;44:728-36.

42. Norton C, Kamm MA. Anal sphincter biofeedback and pelvic floor exercises for faecal incontinence in adults: a systematic review. Aliment Pharmacol Ther 2001;15:1147-54.

43. Fynes MM, Marshall K, Cassidy M, Behan M, Walsh D, O’Connell $\mathrm{PR}$, et al. A prospective, randomized study comparing the effect of augmented biofeedback with sensory biofeedback alone on fecal incontinence after obstetric trauma. Dis Colon Rectum 1999; 42:753-8.

44. Osterberg A, Graf W, Eeg-Olofsson K, Hålldén M, Påhlman L. Is electrostimulation of the pelvic floor an effective treatment for neurogenic faecal incontinence? Scand J Gastroenterol 1999;34: 319-24.

45. Heymen S, Scarlett Y, Jones K, Ringel Y, Drossman D, Whitehead WE. Randomized controlled trial shows biofeedback to be superior to pelvic floor exercises for fecal incontinence. Dis Colon Rectum 2009;52:1730-7.

46. Norton C, Chelvanayagam S, Wilson-Barnett J, Redfern S, Kamm MA. Randomized controlled trial of biofeedback for fecal incontinence. Gastroenterology 2003;125:1320-9.

47. Ganio E, Luc AR, Clerico G, Trompetto M. Sacral nerve stimulation for treatment of fecal incontinence: a novel approach for intractable fecal incontinence. Dis Colon Rectum 2001;44:619-29.

48. Markland AD, Jelovsek JE, Whitehead WE, Newman DK, Andy UU, Dyer K, et al. Improving biofeedback for the treatment of fecal incontinence in women: implementation of a standardized multi-site manometric biofeedback protocol. Neurogastroenterol Motil 2017;29(1). https://doi.org/10.1111/nmo.12906.

49. Matzel KE, Stadelmaier U, Hohenfellner M, Gall FP. Electrical stimulation of sacral spinal nerves for treatment of faecal incontinence. Lancet 1995;346:1124-7.

50. Roy AL, Gourcerol G, Menard JF, Michot F, Leroi AM, Bridoux V. Predictive factors for successful sacral nerve stimulation in the treatment of fecal incontinence: lessons from a comprehensive treatment assessment. Dis Colon Rectum 2014;57:772-80.

51. Meyer I, Richter HE. An evidence-based approach to the evaluation, diagnostic assessment and treatment of fecal incontinence in women. Curr Obstet Gynecol Rep 2014;3:155-64.

52. Kenefick NJ, Christiansen J. A review of sacral nerve stimulation for the treatment of faecal incontinence. Colorectal Dis 2004;6: 75-80.

53. Melenhorst J, Koch SM, Uludag O, van Gemert WG, Baeten CG. Sacral neuromodulation in patients with faecal incontinence: results of the first 100 permanent implantations. Colorectal Dis 2007;9:725-30.

54. Malouf AJ, Vaizey CJ, Nicholls RJ, Kamm MA. Permanent sacral nerve stimulation for fecal incontinence. Ann Surg 2000;232:1438.

55. Jarrett ME, Matzel KE, Christiansen J, Baeten CG, Rosen H, Bittorf $\mathrm{B}$, et al. Sacral nerve stimulation for faecal incontinence in patients with previous partial spinal injury including disc prolapse. Br J Surg 2005;92:734-9.

56. Melenhorst J, Koch SM, Uludag O, van Gemert WG, Baeten CG. Is a morphologically intact anal sphincter necessary for success with sacral nerve modulation in patients with faecal incontinence? Colorectal Dis 2008;10:257-62.

57. Holzer B, Rosen HR, Novi G, Ausch C, Hölbling N, Schiessel R. Sacral nerve stimulation for neurogenic faecal incontinence. $\mathrm{Br} J$ Surg 2007;94:749-53.

58. Hetzer FH, Bieler A, Hahnloser D, Löhlein F, Clavien PA, Demartines N. Outcome and cost analysis of sacral nerve stimulation for faecal incontinence. Br J Surg 2006;93:1411-7.

59. Durdey P. Incontinence. In: Philiips RK, editor. A companion to specialist surgical practice: colorectal surgery. 4th ed. London: Saunders Elsevier; 2009. p. 175-92.

60. Wexner SD, Coller JA, Devroede G, Hull T, McCallum R, Chan M, et al. Sacral nerve stimulation for fecal incontinence: results of a 120-patient prospective multicenter study. Ann Surg 2010;251: 441-9.

61. Moya P, Parra P, Arroyo A, Peña E, Benavides J, Calpena R. Sacral nerve stimulation versus percutaneous posterior tibial nerve stimulation in the treatment of severe fecal incontinence in men. Tech Coloproctol 2016;20:317-9.

62. Thin NN, Taylor SJ, Bremner SA, Emmanuel AV, Hounsome N, Williams NS, et al. Randomized clinical trial of sacral versus percutaneous tibial nerve stimulation in patients with faecal incontinence. Br J Surg 2015;102:349-58.

63. Knowles CH, Horrocks EJ, Bremner SA, Stevens N, Norton C, O'Connell PR, et al. Percutaneous tibial nerve stimulation versus sham electrical stimulation for the treatment of faecal incontinence in adults (CONFIDeNT): a double-blind, multicentre, 
pragmatic, parallel-group, randomized controlled trial. Lancet 2015;386:1640-8.

64. Thomas GP, Dudding TC, Rahbour G, Nicholls RJ, Vaizey CJ. A review of posterior tibial nerve stimulation for faecal incontinence. Colorectal Dis 2013;15:519-26.

65. Tjandra JJ, Lim JF, Matzel K. Sacral nerve stimulation: an emerging treatment for faecal incontinence. ANZ J Surg 2004;74:1098106.

66. Altomare DF, Ratto C, Ganio E, Lolli P, Masin A, Villani RD. Long-term outcome of sacral nerve stimulation for fecal incontinence. Dis Colon Rectum 2009;52:11-7.

67. Benezech A, Bouvier M, Vitton V. Faecal incontinence: current knowledges and perspectives. World J Gastrointest Pathophysiol 2016;7:59-71.

68. Rodrigues FG, Chadi SA, Cracco AJ, Sands DR, Zutshi M, Gurland B, et al. Faecal incontinence in patients with a sphincter defect: comparison of sphincteroplasty and sacral nerve stimulation. Colorectal Dis 2017;19:456-61.

69. Duelund-Jakobsen J, Lundby L, Lehur PA, Wyart V, Laurberg S, Buntzen $S$. Is the efficacy of sacral nerve stimulation for faecal incontinence dependent on the number of active electrode poles achieved during permanent lead insertion? Colorectal Dis 2016; 18:0414-9.

70. Thin NN, Horrocks EJ, Hotouras A, Palit S, Thaha MA, Chan CL, et al. Systematic review of the clinical effectiveness of neuromodulation in the treatment of faecal incontinence. Br J Surg 2013; 100:1430-47.

71. Thaha MA, Abukar AA, Thin NN, Ramsanahie A, Knowles CH. Sacral nerve stimulation for faecal incontinence and constipation in adults. Cochrane Database Syst Rev 2015;(8):CD004464.
72. Williams NS, Patel J, George BD, Hallan RI, Watkins ES. Development of an electrically stimulated neoanal sphincter. Lancet 1991;338:1166-9.

73. Baeten CG, Konsten J, Spaans F, Visser R, Habets AM, Bourgeois IM, et al. Dynamic graciloplasty for treatment of faecal incontinence. Lancet 1991;338:1163-5.

74. Salmons S, Vrbová G. The influence of activity on some contractile characteristics of mammalian fast and slow muscles. J Physiol 1969;201:535-49.

75. Sielezneff I, Malouf AJ, Bartolo DC, Pryde A, Douglas S. Dynamic graciloplasty in the treatment of patients with faecal incontinence. Br J Surg 1999;86:61-5.

76. Mavrantonis C, Billotti VL, Wexner SD. Stimulated graciloplasty for treatment of intractable fecal incontinence: critical influence of the method of stimulation. Dis Colon Rectum 1999;42:497504.

77. Madoff RD, Rosen HR, Baeten CG, LaFontaine LJ, Cavina E, Devesa $\mathrm{M}$, et al. Safety and efficacy of dynamic muscle plasty for anal incontinence: lessons from a prospective, multicenter trial. Gastroenterology 1999;116:549-56.

78. Mundy L, Merlin TL, Maddern GJ, Hiller JE. Systematic review of safety and effectiveness of an artificial bowel sphincter for faecal incontinence. Br J Surg 2004;91:665-72.

79. Melenhorst J, Koch SM, van Gemert WG, Baeten CG. The artificial bowel sphincter for faecal incontinence: a single centre study. Int J Colorectal Dis 2008;23:107-11.

80. Lehur PA, Wyart V, Riche VP. SaFaRI: sacral nerve stimulation versus the Fenix ${ }^{\circledR}$ magnetic sphincter augmentation for adult faecal incontinence: a randomised investigation. Int J Colorectal Dis 2016;31:1505. 